\title{
The application of Mixed Teaching Mode in Linux Network Programming
} Jitong Zhang ${ }^{1,2}$

\author{
${ }^{1}$ School of Information Engineering, Zhengzhou University of Industrial Technology, Zhengzhou \\ Henan 451150, PR China
}

${ }^{2}$ Machine learning and Data researching Institute, Zhengzhou University of Industrial Technology, Zhengzhou Henan 451150, PR China

a57478337@qq.com

Keywords: Linux; Network programming; MOOC; SPOC

\begin{abstract}
With the development of information technology, the use of information technology to promote the reform of the teaching model has been the community and the education sector generally recognized. This paper points out the necessity of reforming the teaching model from the traditional classroom drawbacks, and then talks about the application of Ubuntu learning, MOOC, SPOC and mixed teaching mode in Linux network programming.
\end{abstract}

\section{Introduction}

With the development of information technology, the use of information technology to promote the reform of the teaching model has been the community and the education sector generally agreed, with the MOOC (Mu), Mini-Course (micro class), SPOC (private lessons), MOOL (public open online laboratory) and other online curriculum platform for the establishment, rise and development, information technology in education and teaching reform practice in the increasingly prominent position[1,2,3]. The state in the "Education Plan"[4] in the education of information technology, pointed out that information technology has a revolutionary impact on the development of education, which determines the information technology on education and teaching reform and development of strategic position[5,6]. How to make use of information technology to achieve flexible and personalized learning methods, how to meet the individual needs of learning and development, how to make good use of information technology to promote the reform of open university teaching model, these three are the major university construction needs to pay attention to the main problem.

\section{Traditional Linux Network Programming Classroom}

Traditional Linux network programming classroom is mainly based on the teacher's active teaching and passive reception of students as the main features, teachers tend to focus on language and knowledge of the inculcation to achieve the teaching of knowledge, in the teaching process, the dominant position of teachers, and students The dominant position is often overlooked. In this teaching mode of classroom teaching is often too rigid, teachers engage in "one speech", in accordance with the order of the book chapters to teach, and each lesson from the beginning to talk about the end of the student's learning status is not fully reflected and respected, Even if they have their own views in the learning process, and often have no chance to express. Therefore, the traditional teaching mode seriously neglected the students 'subjective position in teaching, ignoring the students' psychological development needs, and severely bound the enthusiasm, initiative and creativity of students to study this course. Resulting in many students do not understand, learn not, 
even if learned, and its ability to analyze and solve problems can not be improved, let alone improve their overall quality.

\section{Ubiquitous Learning in Linux Network Programming}

In the study, as the name implies refers to all-time communication, ubiquitous learning, is any kind of person can at any time, any time to obtain any information needed[7]. To enable students to have a resource and environment in the classroom, teachers must first use the modern information technology means to create an intelligent learning environment and platform for students to have a study of the Linux network programming course Resources, teachers can collect from the Internet to organize some excellent e-books, teaching video and related training and training topics, through the teacher's personal network platform or by means of the school's network platform, under the students to study and training for students to provide a Seamless learning platform and learning resources. The goal of the study is to provide students with an educational and learning environment that allows students to learn from any terminal, anytime, anywhere, and to achieve a more effective student center education. In the pan in the learning environment, students according to their needs in a variety of space, in a variety of ways to learn, that is, all the actual space to become learning space.

\section{Application of MOOC in Linux Network Programming}

It can be used to expand the students' knowledge, broaden the students' horizons, understand the development trend of Linux network programming, and improve the enthusiasm and initiative of students' learning. This process is Students reflect the autonomy of learning, teachers can not be effective supervision, is a loose way of learning. The use of MOOC way, first of all to the Linux network programming teaching content decomposition, the entire content is divided into different knowledge points, each knowledge points can be divided into 6 to 20 minutes can explain the knowledge of debris. And then recorded the video as a video, according to the Linux network programming content and teaching progress, teachers through the network platform for the release of the relevant video, while the student's learning process to track the record, each knowledge points are equipped with the appropriate exercises For testing purposes, used to detect learning results. Open the online discussion area for students to discuss the use, which also requires teachers to pay close attention to the discussion of students in order to guide students in the formal classroom to discuss or solve some students can not solve the problem. This can also be used on the Internet better related MOOC resources, if there is no relevant online curriculum resources, you need to do the teacher himself. In addition, the use of MOOC teachers need to be deeply involved in student learning and effective supervision.

\section{Application of SPOC in Linux Network Programming}

The current SPOC teaching, mainly for students in the school set up, is a combination of classroom teaching and online teaching mixed learning model, under the course of the MOOC lectures video (or at the same time using its online evaluation and other functions), the implementation of the classroom Flip classroom teaching. The basic process is that teachers to Linux network programming video materials as class assignments to students, and then in the physical classroom teaching to answer students in the study of the problems encountered, to understand the students grasp the knowledge of the situation, which has not yet been mastered Class together with students 
to deal with assignments or other questions. In general, the classroom is based on student discussion, the teacher to guide and classroom control, and sometimes according to the actual situation, such as most students are unable to understand this knowledge, or understand the case, the teacher to use the traditional classroom The way to the relevant content and knowledge points for further explanation and analysis, until the students understand so far. In general, teachers can freely set and control the progress, rhythm and scoring system of the course and the form of classroom organization according to their own preferences and the needs of the students. This is the mixed teaching mode. At the same time require learners to ensure that learning time and learning intensity, participate in online discussions, complete the required operations and examinations, etc., will pass the corresponding credits.

\section{Summary}

Linux network programming is an important professional course of computer science. This course mainly introduces the knowledge and method of network programming with socket socket in $\mathrm{C}$ language. From the content can be seen "Linux network programming" This course involves more content, the higher the professional knowledge of students, both require students to master the use of Linux operating system and master C language programming knowledge and programming skills, Students are also required to understand the TCP/IP protocol stack and the Linux operating API. This is the three institutions of students, learning more difficult. So if the use of traditional classroom teaching, students often do not understand can not keep up, the enthusiasm of learning is not high, the classroom atmosphere is boring, learning effect is not ideal. It is imperative to reform the teaching model of Linux network programming. Make full use of contemporary information technology platform, to create a pan in the learning environment, the use of modern teaching mode, according to the actual situation of the school using MOOC plus SPOC class teaching organization is the inevitable trend of modern teaching reform.

\section{References}

[1] Da-wei Qu, Peng Zhang . MOOC and higher school teaching reform research. Modern education science, Vol.5(2015),No.5,P.119-122.(In Chinese)

[2] Fang Lu, Xuesong Yin and Jixian Zhang. Design of Seamless Learning Environment in the View of Open University. Distance Education Journal, Vol.2(2016),No.2,P.39-48.(In Chinese)

[3] Bin He, Yang Cao. SPOC: MOOC-based teaching process innovation. China Audio-Visual Education, Vol.3(2015),No.4,P.52.(In Chinese)

[4] Improving Learning in MOOCs with Cognitive Science. Williams,J.J. http://people.csail.mit.edu/zp/moocshop2013/paper23.pdf . 2013

[5] Harvard $X$ Set To Launch Second SPOC. Hashmi, A.H. http://harvardx.harvard.edu/links/harvardx-set-launch-second-spocharvard-crimson-amna-h-has hmi-september-16-2013. 2014

[6] Small online course. Wikipedia. http://en.wikipedia.org/wiki/Small_private_online_course. 2014

[7] MOOCs-Best practices and worst challenges. Hoffmann, R. http://www.aca-secretariat.be/fileadmin/aca_docs/images/members/Rolf_Hoffmann.pdf . 2014

[8] Are we really enter into post-Mooc era? ICEF Monitor. http://monitor.icef.com/2013/11/are-we-already-entering-a-post-moocera. 2014 
[9] Online leaning:MOOC challenges and success factors. Hussain,M. http://www.onlineeconomy.org/online-learning-moocchallenges-and-success-factors . 2014

[10]Things You Should Know About MOOCs.
http://www.educause.edu/library/resources/7-things-you-should-know-aboutmoocs. 2014 